different segmentation algorithms and observer training levels. Eur J Radiol 2007;64:285-95.

9. Shinagawa N, Yamazaki K, Onodera Y, et al. Factors related to diagnostic sensitivity using an ultrathin bronchoscope under CT guidance. Chest 2007; 131:549-53.

10. Vincent BD, Fraig M, Silvestri GA. A pilot study of narrow-band imaging compared to white light bronchoscopy for evaluation of normal airways and premalignant and malignant airways disease. Chest 2007;131:1794-9.

11. Coxson HO, Quiney B, Sin DD, et al. Airway wall thickness assessed using computed tomography and optical coherente tomography. Am J Respir Crit Care Med 2008:177:1201-6.

12. Shedden K, Taylor JMG, Enkemann SA, et al. Gene expression-based survival prediction in lung adenocarcinoma: a multi-site, blinded validation study. Nat Med 2008;14:822-7.
13. Spira A, Beane JE, Shah V, et al. Airway epithelial gene expression in the diagnostic evaluation of smokers with suspect lung cancer. Nat Med 2007:13:361-6.

14. Yanagisawa K, Shyr Y, Xu BJ, et al. Proteomic patterns of tumour subsets in non-small-cell lung cancer. Lancet 2003:362:433-9.

15. Yildiz PB, Shyr Y, Rahman JSM, et al. Diagnostic accuracy of MALDI mass spectrometric análysis of unfractionated serum in lung cancer. J Thorac Oncol 2007;2:893-901

16. Brock MV, Hooker CM, Ota-Machida E, et al. DNA methylation markers and early recurrence in stage I lung cancer. N Engl J Med 2008;358:1118-28.

17. Maheswaran S, Sequist LV, Nagrath S, et al. Detection of mutations in EGFR in circulating lungcancer cells. N Engl J Med 2008;359:1-12.

18. Chapman CJ, Murray A, McElveen JE, et al. Autoantibodies in lung cancer: possibilities for early detection and subsequent cure. Thorax 2008;63:228-33.

19. Chen X, Ba Y, Ma L, et al. Characterization of microRNAs in serum: a novel class of biomarkers for diagnosis of cancer and other diseases. Cell Res 2008;18:997-1006.

20. Carpagnano GE, Foschino-Barbaro MP Spanevello A, et al. 3p microsatellite signature in exhaled breath condensate and tumor tissue of patients with lung cancer. Am J Respir Crit Care Med 2008;177:337-41.

21. Mazzone PJ. Analysis of volatile organic compounds in the exhaled breath for lung cancer diagnosis. J Thorac Oncol 2008;3:774-80.

22. Westhoff M, Litterst $P$, Freitag $L$, et al

Ion mobility spectrometry for the detection of volatile organic compounds in exhaled breath of patients with lung cancer: results of a pilot study. Thorax 2009;64:744-8.

\title{
The $\beta_{2}$ receptor and airway hyper-responsiveness: are sensory nerves involved?
}

\section{Clive Page}

The use of $\beta_{2}$ agonists for the control of symptoms is central to the treatment of patients with asthma. However, there is controversy surrounding the regular use of this drug class as numerous studies have demonstrated a variety of changes that can be considered unwanted attributes, particularly when these drugs are used regularly as monotherapy. These include increased bronchial hyper-responsiveness (BHR) to inhaled contractile agents ${ }^{1}$ and an increase in the allergeninduced early ${ }^{2}$ and late asthmatic response $^{3}$ following regular treatment with short-acting $\beta_{2}$ agonists (SABAs). Furthermore, a number of studies have suggested that regular treatment with inhaled SABAs and long-acting $\beta_{2}$ agonists (LABAs) by inhalation leads to a loss of bronchoprotection ${ }^{4}$ and with salmeterol treatment an excess mortality in patients with asthma, ${ }^{6}$ a trend also observed with regular treatment with formoterol. ${ }^{7}$ This has led the Food and Drug Administration (FDA) to post black-box warnings on all medicines containing these LABAs.

Christian Virchow and colleagues from Rostock have provided data (see page 763) on a potential mechanism as to how regular treatment with salmeterol can

Correspondence to: Professor Clive Page, Sackler Institute of Pulmonary Pharmacology, Division of Pharmaceutical Sciences, King's College London, Guy's Campus, London Bridge, London SE1 9RT, UK; clive.page@kcl.ac.uk paradoxically increase $\mathrm{BHR} .^{8}$ Eighteen patients with mild allergic asthma inhaled standard doses of salmeterol xinafoate for 2 weeks, followed by 2 weeks of treatment with the combination of fluticasone and salmeterol xinafoate. There was no overall statistically significant change in $\mathrm{BHR}$ for the whole group receiving monotherapy with salmeterol. However, $67 \%$ of the patients showed a modest increase in BHR as measured by a lowered $\mathrm{PC}_{20}$ (provocative concentration of histamine causing a $20 \%$ fall in the forced expiratory volume in $1 \mathrm{~s}$ ) following monotherapy with salmeterol compared with baseline. This contrasted with a statistically significant improvement in BHR following the combination therapy. The levels of brain-derived neurotrophic factor (BDNF) were elevated in both serum and platelets obtained from patients receiving monotherapy with salmeterol, and the changes in BDNF levels correlated with the changes in $\mathrm{PC}_{20}$, although the levels of BDNF decreased significantly and there was no such correlation with changes in $\mathrm{PC}_{20}$ in the patients receiving the combination therapy. The changes in $\mathrm{PC}_{20}$ following monotherapy with inhaled salmeterol did not show a correlation with known $\beta_{2}$ receptor polymorphisms.

A number of other investigators have suggested a role for BDNF in BHR as this is a mediator that is increased in subjects with asthma, both in the lung ${ }^{9}$ and in platelets, ${ }^{10}$ and which at least in animal models can induce BHR associated with changes in neuronal activity. ${ }^{11}$ In patients with asthma, the systemic levels of BDNF are also elevated, whilst they correlate with BHR. ' Increases in BDNF levels in the lung following allergen challenge of patients with asthma can be reduced by glucocorticosteroids. ${ }^{12}$ Airway sensory nerves have also been implicated in the pathogenesis of BHR induced by a number of stimuli, ${ }^{13}$ including treatment with regular $\beta_{2}$ agonists, ${ }^{14}$ and it is of particular interest that platelet activation has also been observed to play a central role in allergen-induced BHR experimentally, ${ }^{15} 16$ supporting the observations of Virchow and colleagues in the present study. Interestingly, salmeterol enhanced the secretion of BDNF from tumour necrosis factor $\alpha(T N F \alpha)$-stimulated human peripheral blood mononuclear cells, whilst BDNF secretion was inhibited by fluticasone.

Clearly it would be of interest to see if salmeterol also caused an increase in BDNF secretion from platelets, thus allowing a clearer link between platelet activation, BDNF and the exacerbation of BHR observed following monotherapy with regular inhaled salmeterol. Whilst the acute benefits of $\beta_{2}$ agonist therapy are well accepted, the worsening of asthma control with chronic $\beta_{2}$ agonist treatment is not as well accepted, with a recent study reinforcing the safety of regular $\beta_{2}$ agonists use. ${ }^{17}$ Nonetheless, a number of mechanisms have been put forward to explain worsening asthma control with regular $\beta_{2}$ agonist treatment, including increased antigen burden, ${ }^{18}$ increased BHR induced by the (+) enantiomer $^{14}$ and loss of bronchoprotection. ${ }^{4}$ Recently, the role of $\beta_{2}$ receptors in asthma has become more complicated with the recognition that $\beta$-blockers, which have traditionally been contraindicated in the treatment of patients with 
asthma, can improve BHR when administered chronically to patients with mild asthma. ${ }^{19}$ This research has many parallels with the use of $\beta$-blockers in the treatment of patients with heart failure where this class of drug was once contraindicated as acute dosing produced adverse effects in such patients. ${ }^{20}$ It was then subsequently recognised that chronic dosing with $\beta$-blockers was beneficial in patients with heart failure, and the use of this drug class is now considered a central part of standard treatment guidelines. So-called "paradoxical pharmacology", where there may be differential effects of acute versus chronic dosing of a given class of drug, would seem to be a very important issue when considering the use of drugs that recognize the $\beta_{2}$ receptor.

Furthermore, given that it has been recently suggested that some $\beta$-blockers act as inverse agonists at the $\beta_{2}$ receptor and activate novel signalling pathways that are required for the full asthma phenotype in mice, ${ }^{22}$ it would seem time to challenge the dogma that activation of $\beta_{2}$ receptors chronically is a good thing. If nothing else, the study by Virchow and colleagues provides further support for why monotherapy with $\beta_{2}$ receptor agonists has no role in the treatment of patients with asthma.

Competing interests: $\mathrm{CP}$ is a co-founder of Verona Pharma which has an interest in developing novel drugs for treating respiratory diseases.
Provenance and peer review: Commissioned; not externally peer reviewed.

Thorax 2009;64:738-739. doi:10.1136/thx.2009.113506

\section{REFERENCES}

1. Page CP, Spina D. Beta2-agonists and bronchial hyperresponsiveness. Clin Rev Allergy Immunol 2006; 31:143-62

2. Cockcroft DW, McParland CP, Britto, et al. Regular inhaled salbutamol and airway responsiveness to allergen. Lancet 1993;342:833-37.

3. Gauvreau GM, Jordana M, Watson RM, et al. Effect of regular inhaled albuterol on allergen-induced late responses and sputum eosinophils in asthmatic subjects. Am J Crit Care Med 1997;156:1738-45.

4. Cheung D, Timmers MC, Zwinderman AH, et al. Long term effects of a long acting beta 2 adrenoceptor agonist, salmeterol, on airway hyperresponsiveness in patients with mild asthma. $N$ Engl J Med 1992:327:1198-203.

5. O'Connor BJ, Aikman SL, Barnes PJ. Tolerance to the non-bronchodilator effects of inhaled beta 2 agonists in asthma. N Engl J Med 1992;327:1204-8.

6. Nelson HS, Weiss ST, Bleeker ER, et al The salmeterol multicentre asthma research trial: a comparison of usual pharmacotherapy for asthma or usual pharmacotherapy plus salmeterol. Chest 2006;129:15-26.

7. Sears MR, Ottosson A, Radner F, et al. Long acting beta agonists: a review of formoterol safety data from asthma clinical trials. Eur Resp J 2009;33:21-32.

8. Lommatzsch $\mathbf{M}$, Lindner $Y$, Edner $A$, et al. Adverse effects of salmeterol in asthma: a neuronal perspective. Thorax 2009;64:763-9.

9. Virchow JC, Julius $\mathrm{P}$, Lommatzsch $\mathrm{M}$, et al. Neurotrophins are increased in bronchoalveolar lavage fluid after segmental allergen provocation. Am J Respir Crit Care Med 1998;158:2002-5.

10. Lommatzsch M, Schloetcke K, Klotz J, et al. Brainderived neurotrophic factor in platelets and airflow limitation in asthma. Am J Respir Crit Care Med 2005;171:115-20.
11. Braun A, Lommatzsch M, Neuhaus-Steinmetz $\mathrm{U}$, et al. Brain-derived neurotrophic factor (BDNF) contributes to neuronal dysfunction in a model of allergic airway inflammation. $\mathrm{Br} \mathrm{J}$ Pharmacol 2004;141:431-40.

12. Noga $\mathbf{0}$, Hanf G, Schaper $C$, et al. The influence of inhalative corticosteroids on circulating nerve growth factor, brain-derived neurotrophic factor and neurotrophin-3 in allergic asthmatics. Cli Exp Allergy 2001;31:1906-12.

13. Spina D, Page CP. Asthma-a need for a rethink? Trends Pharmacol Sci 2002;23:311-5.

14. Keir S, Page C, Spina D. Bronchial hyperresponsiveness induced by chronic treatment with albuterol: role of sensory nerves. J Allergy Clin Immunol 2006:118:551-9.

15. Coyle AJ, Page CP, Atkinson L, et al. The requirement of platelets for allergen-induced late asthmatic airways obstruction. Am Rev Respir Dis 1990;142:587-93.

16. Pitchford SC, Riffo-Vasquez $Y$, Sousa A, et al. Platelets are necessary for airway wall remodeling in a murine model of chronic allergic inflammation. Blood 2004;103:639-47.

17. Drazen JM, O'Byrne PM. Risks of long-acting betaagonists in achieving asthma control. N Engl J Med 2009;360:1671-2.

18. Page CP. One explanation of the asthma paradox: inhibition of natural anti inflammatory mechanisms by beta 2-agonists. Lancet 1991;337:717-20.

19. Hanania NA, Singh S, El-Wali R, et al. The safety and effects of the beta blocker, nadolol, in mild asthma: an open label pilot study. Pulm Pharmacol Ther 2008;21:134-41

20. Bond R, Spina D, Parra S, et al. Getting to the heart of asthma: can beta blockers be useful to treat asthma? Pharmacol Ther 2007;115:360-74.

21. Bond RA. Is paradoxical pharmacology a strategy worth pursuing? Trends Pharmacol Sci 2001;22:273-6.

22. Nguyen LP, Lin R, Parra S, et al. Beta2-adrenoceptor signaling is required for the development of an asthma phenotype in a murine model. Proc Natl Acad Sci USA 2009;106:2435-40.

\section{Mechanisms of adverse effects of $\beta$-agonists in asthma}

\section{Sebastian L Johnston, Michael R Edwards}

Short-acting $\beta$-agonist (SABA) drugs have been mainstays of asthma therapy for many decades and are recommended treatment at all levels of asthma severity, as they provide prompt relief of asthma symptoms through smooth muscle relaxation and, thereby, bronchodilatation. At all levels of asthma severity more severe than mild intermittent, SABAs are recommended to be taken as required for relief

Department of Respiratory Medicine, National Heart and Lung Institute, MRC \& Asthma UK Centre in Allergic Mechanisms of Asthma, Imperial College London, London, UK

Correspondence to: Professor Sebastian L Johnston, Department of Respiratory Medicine, National Heart and Lung Institute, Imperial College London, Norfolk Place, London W2 1PG, UK; s.johnston@imperial.ac.uk of symptoms in conjunction with inhaled corticosteroids (ICSs) taken as regular maintenance treatment. However, in mild asthma SABAs are recommended as monotherapy without concomitant ICS therapy, and in both mild and more severe asthma, greatly increased SABA use at times of asthma exacerbation is almost universal. Here we discuss the safety of inhaled $\beta$-agonist monotherapy in asthma and argue against the continued use of $\beta$ agonist monotherapy (both short and long acting) in the absence of concomitant ICS therapy in a combination inhaler.

Several epidemiological studies link overuse of SABA therapies at times of asthma exacerbation with increased risk of hospitalisation or mortality. ${ }^{12}$ The mechanisms underlying this increased risk have not been clearly determined, but are most likely to involve complex mechanisms including delays in seeking medical care, potential cardiac (tachycardia) and metabolic (hypokalaemia) adverse effects as well as possible effects on underlying asthma severity. Although fenoterol, the SABA linked with the epidemic of asthma mortality in the early 1980s in New Zealand $^{3}$ and some other countries, ${ }^{4}$ has greater cardiac effects than other SABAs, the reduction in hospitalisations due to asthma exacerbations (along with a reduction in asthma mortality) following the withdrawal of high dose fenoterol in New Zealand in 1990 suggested that the reduction in asthma mortality was not wholly due to reduction in cardiac/ metabolic side effects, but probably also due to an effect on disease severity (because if the reduction in mortality were due to reduction in cardiac side effects, the rate of hospitalisations due to asthma exacerbations should have remained unchanged). ${ }^{5}$ 